Research Article

\title{
Knowledge attitude and practice of haemovigilance among doctors in tertiary care hospital in Nagpur, Maharashtra, India
}

\author{
Amit P. Date ${ }^{1 *}$, Anjali A.Date ${ }^{2}$, Amruta V. Dashputra ${ }^{1}$, Archana S. Borkar ${ }^{1}$
}

\begin{abstract}
${ }^{1}$ Department of Pharmacology, ${ }^{2}$ Department of Physiology, NKP Salve Institute of Medical sciences, Hingna Road, Digdoh Hills, Nagpur, Maharashtra, India
\end{abstract}

Received: 24 February 2016

Accepted: 21 March 2016

*Correspondence to:

Dr. Amit Padmakar Date,

Email: amit_date9173

@yahoo.co.in

Copyright: (C) the author(s), publisher and licensee Medip Academy. This is an openaccess article distributed under the terms of the Creative Commons Attribution NonCommercial License, which permits unrestricted noncommercial use, distribution, and reproduction in any medium, provided the original work is properly cited.

\begin{abstract}
Background: Haemovigilance program of India was launched on December 2012 and is a comprehensive, and a well-structured approach to collect, collate, and analyse data to address the issues of adverse reactions associated with blood transfusion. The information thus collected would facilitate corrective and preventive actions to be taken to minimize the potential risk associated blood collection processing and transfusion to patients. Considering the deep concern over the under-reporting of transfusion reactions prevailing among the doctors, the present study was done to know the knowledge attitude and practice (KAP) of haemovigilance among doctors.

Methods: The present study was a cross sectional questionnaire based study, which included doctors of a tertiary care hospital. The purpose of the questionnaire was to know awareness of doctors regarding haemovigilance programme of India. With this study we also tried to identify the factors responsible for underreporting of transfusion reactions and to find out the possible ways to improve reporting of transfusion reactions.

Results: (38.88\%) and (30\%) of the responders were aware of the haemovigilance programme and transfusion reaction reporting centre respectively. Reporting of transfusion reaction was poor $22.22 \%$ among the respondents. According to respondents creating awareness about haemovigilance by conducting continuing medical education (CMEs), and training to healthcare professionals would lead to improvement in reporting of transfusion reactions. Complacency and ignorance were the main factors which discouraged transfusion reaction reporting by doctors.

Conclusions: Increasing awareness of haemovigilance among doctors and training on reporting transfusion reactions would likely improve spontaneous reporting and help to strengthen the blood transfusion system.
\end{abstract}

Keywords: Haemovigilance, Transfusion reaction reporting, Underreporting

\section{INTRODUCTION}

The word 'haemovigilance' (he'movigilance in French) was coined in France in 1991 in analogy to the already existing term 'pharmacovigilance'. It is derived from the Greek word 'haema' blood and the Latin word 'vigilans' watchful. Haemovigilance is defined as 'a set of surveillance procedures covering the whole transfusion chain from the collection of blood and its components to the follow-up of its recipients, intended to collect and assess information on unexpected or undesirable effects resulting from the therapeutic use of labile blood products, and to prevent their occurrence and recurrence'. Haemovigilance is an important part of the quality system for blood transfusion. It implies methods for identifying errors, adverse events and reactions including alert systems, investigation of complaints, traceability systems, notification systems and audits of practice. ${ }^{1}$

Haemovigilance systems, depending upon the country, are governed either by regulators (e.g., France, Germany, Switzerland), blood manufacturers (e.g., Japan, Singapore, South Africa), medical societies (e.g., Netherlands, UK), or public health authorities including regulators (e.g., Canada). ${ }^{2}$

Member states of the European Union have to implement haemovigilance program with reporting to a central office 
as per the commission directive. ${ }^{3-5}$ Among the Asian countries, a well-established haemovigilance system is lacking and there is paucity of data on haemovigilance except for Japan, which has published a report on adverse reactions. ${ }^{6}$

Indian pharmacopoeia commission in collaboration with national institute of biological has launched haemovigilance programme of India (HvPI) across the country under its pharmacovigilance programme of India (PvPI). Haemovigilance programme launched on $10^{\text {th }}$ December 2012 has already enrolled 134 medical colleges. A central haemovigilance system involves all relevant stakeholders and coordinates various activities between blood banks blood, transfusion services, hospital health care professionals, transfusion committees, regulatory agencies and national health authorities. ${ }^{7}$

Extension of haemovigilance to the regional and global level by linking it to international haemovigilance network would further strengthen it. The members of haemovigilance advisory committee, core group signal review panel, quality review panel, and training panel have important role to play in achieving these objectives. ${ }^{7}$

A system of haemovigilance is dependent on traceability of blood and blood products from donors to recipients, spontaneous reports of transfusion adverse events/reactions, rigorous management of information related to the transfusion process. Information generated through this system is a key to introduce required changes in the transfusion policies, improve transfusion standards, assist in the formulation of transfusion guidelines to increase the safety and quality of the entire transfusion process. ${ }^{8}$ In the field of patient safety, knowledge of how to prevent harm to the patient during treatment and care is utmost important. Health care errors have common root causes which can be corrected. Most problems are not just a series of random unconnected event. Although each event is unique there are likely to be similarities and patterns in sources of risk which may go unnoticed if incidents are not reported. ${ }^{9,10}$ Haemovigilance is urgent need of country to identify and prevent occurrence of transfusion related reactions so as to improve the patient safety and improve the quality of blood delivered. Reporting transfusion reactions is of paramount importance for the success of a haemovigilance program of a country for generating data on the transfusion reactions occurring. The information thus collected would facilitate corrective and preventive actions to be taken to minimize the potential risk associated blood collection processing and transfusion to patients. Considering the deep concern over the underreporting prevailing among the doctors, the present study was done to know the knowledge attitude and practice (KAP) of haemovigilance among doctors.
The objectives of this study were to assess the knowledge attitude and practice (KAP) of faculty members regarding haemovigilance in tertiary care hospital. And to know about the factors which encourage or discourage transfusion reaction reporting and optimize transfusion process in tertiary care hospital.

\section{METHODS}

The study was done at NKP salve institute of medical sciences and research centre Nagpur, Maharashtra, India to assesses KAP of faculty members regarding haemovigilance, for which a cross sectional, questionnaire based study was done. Predesigned and validated questionnaires were given to faculty of the Institute. Both open and close ended KAP questionnaire which include 18 questions, out of these 9 questions were regarding knowledge, 5 for attitude, 4 for practice about haemovigilance were prepared. After explaining the purpose of the study, the questionnaire was administered to 120 doctors working in pre-clinical, para-clinical and clinical departments. To enhance the response rate, the doctors were requested to complete the questionnaire and hand it back immediately, and those who were busy at that moment were requested to return back the duly filled questionnaires within 1 week. The study was done in the period between July 2014 and December 2014.

\section{Statistical analysis}

Data was collected and results were expressed in percentage.

\section{RESULTS}

Out of total of 120 questionnaires administered to doctors, 90 were duly filled and returned, thus giving a response rate of $75 \%$.

Out of 90 respondent doctors, $70(77.77 \%), 15$ (16.66\%), and $5(5.55 \%)$ were from clinical, para-clinical, and preclinical departments, respectively.

Table 1 shows knowledge among doctors for reporting transfusion reactions. Thirty five $(38.88 \%)$ participants were aware of the existence of HvPI while 27 (30\%) doctors were aware of the centre for reporting of transfusion reaction in Maharashtra.

$58(64.44 \%)$ of the doctors were of opinion that only serious transfusion reaction should be reported. 50 $(55.55 \%)$ of the doctors were of the opinion that they would report transfusion reaction to head of unit/department, 45 (50\%) to the blood bank. 
Table 1: Knowledge among doctors for transfusion reaction reporting $(\mathrm{n}=90)$.

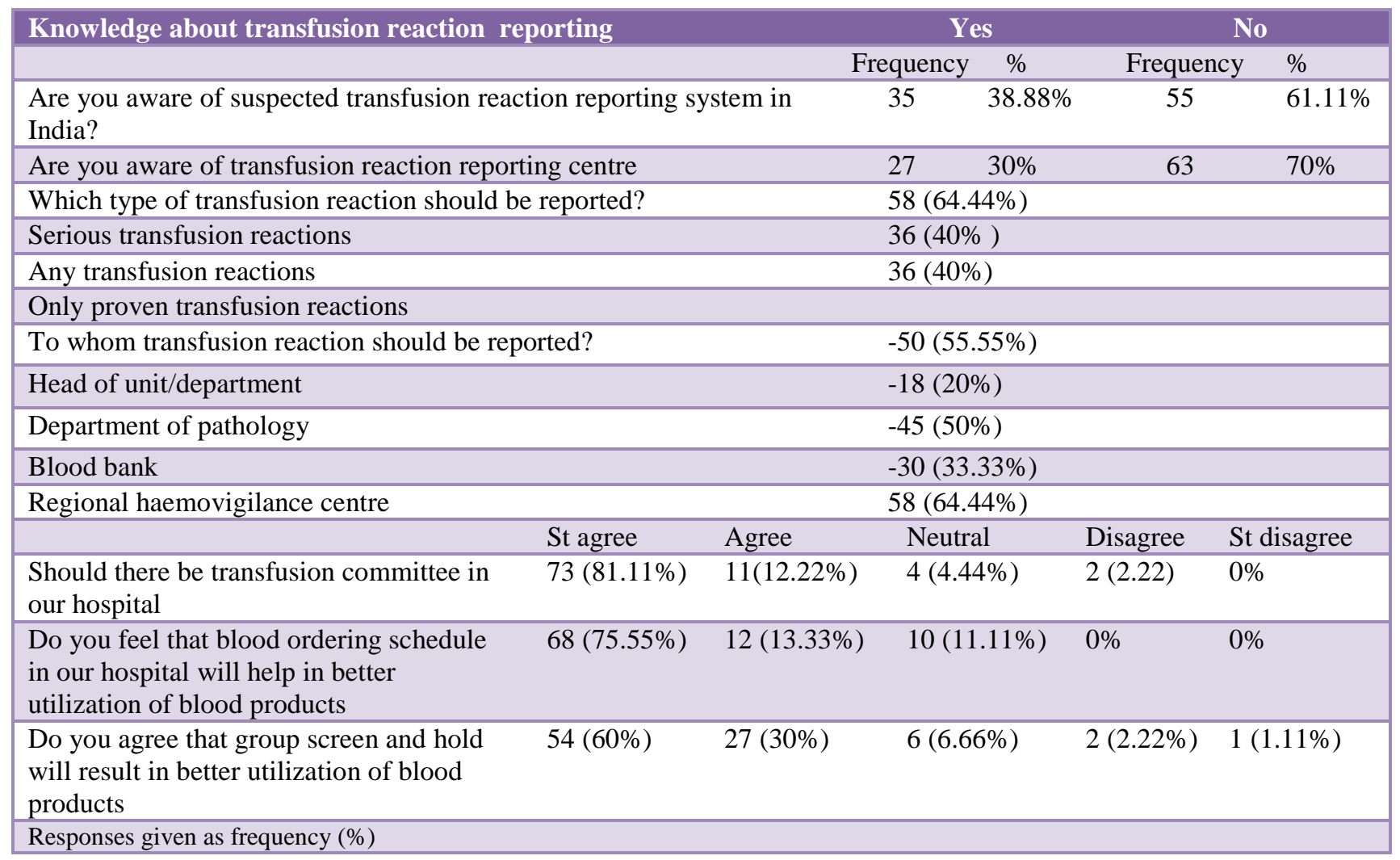

$73(81.11 \%)$ of the doctors strongly agreed that there should be blood transfusion committee in our hospital. 68 $(75.55 \%)$ and $54(60 \%)$ of the doctors strongly agreed that blood ordering schedule and group screen and hold respectively will help in better utilization of blood products.

\section{Table 2: Response among doctors to improve} reporting $(n=90)$.

\begin{tabular}{|lcc|}
\hline \multicolumn{2}{|l}{$\begin{array}{l}\text { Possible ways to improve } \\
\text { transfusion reaction reporting }\end{array}$} & Frequency \\
\hline \multicolumn{2}{|c|}{$\%$} \\
\hline $\begin{array}{l}\text { Reporting of transfusion reactions be } \\
\text { made more easy }\end{array}$ & 67 & 74.44 \\
\hline $\begin{array}{l}\text { Remuneration for transfusion reaction } \\
\text { reporting }\end{array}$ & 44 & 48.88 \\
\hline $\begin{array}{l}\text { Providing electronic form for } \\
\text { submission }\end{array}$ & 47 & 52.22 \\
\hline $\begin{array}{l}\text { Healthcare professionals should be } \\
\text { trained on transfusion reaction } \\
\text { reporting }\end{array}$ & 67 & 74.44 \\
\hline $\begin{array}{l}\text { Continuing medical education(CME) } \\
\text { and refresher study }\end{array}$ & 69 & 76.66 \\
\hline Availability of reporting forms in wards & 45 & 50 \\
\hline
\end{tabular}

Table 2 shows the possible ways in improving transfusion reaction reporting. $69(76.66 \%)$ gave first preference to the continuing medical education (CME) on haemovigilance. Another important way which can improve reporting is training to report transfusion reactions and reporting be made easy 67 (74.44\%).

Table 3: Factors discouraging transfusion reaction reporting $(\mathbf{n}=90)$.

\begin{tabular}{|lcc|}
\hline \multirow{2}{*}{$\begin{array}{l}\text { Factors discouraging to } \\
\text { report transfusion reactions }\end{array}$} & Frequency & $\%$ \\
\hline Did not know how to report & 54 & 60 \\
\hline Did not know where to report & 54 & 60 \\
\hline $\begin{array}{l}\text { Apprehension regarding sending } \\
\text { inappropriate form }\end{array}$ & 56 & 62.22 \\
\hline Busy schedule to fill form & 47 & 52.22 \\
\hline Non remuneration for reporting & 56 & 56.66 \\
\hline $\begin{array}{l}\text { Reporting of previously known } \\
\text { reactions is not required }\end{array}$ & 63 & 70 \\
\hline Due to legal issues & 48 & 53.33 \\
\hline Concerns that report may be wrong & 51 & 56.66 \\
\hline $\begin{array}{l}\text { Busy to look actively for } \\
\text { transfusion reaction }\end{array}$ & 54 & 60 \\
\hline
\end{tabular}

Other encouraging factors like remuneration for transfusion reaction reporting, providing electronic form for submission, availability of reporting forms in wards were quoted by $48.88 \%, 52.22 \%$ and $50 \%$ of responders respectively as the possible ways to improve reporting. 
Table 3 shows the factors that discourage doctor's form reporting transfusion reactions. Maximum doctors were of opinion that reporting of previously known reactions is not required $63(70 \%)$. (Table 4) shows transfusion reaction reporting practice among doctors. $22.22 \%$ of the doctors had reported transfusion reaction. 20\% had attended CME on haemovigilance. $24.44 \%$ had read article on preventability of transfusion reaction. $14.44 \%$ had ever been trained on how to report a transfusion reaction.

Table 4: Practice of transfusion reaction reporting among doctors $(n=90)$.

\begin{tabular}{|c|c|c|c|c|}
\hline \multirow{2}{*}{ Practice of transfusion reaction reporting } & \multicolumn{2}{|l|}{ Yes } & \multicolumn{2}{|c|}{ No } \\
\hline & Frequency & $\%$ & Frequency & $\%$ \\
\hline Have you ever reported any suspected adverse drug reaction if yes where specify. & 20 & 22.22 & 70 & 77.77 \\
\hline Have you attended any CME on haemovigilance? & 18 & 20 & 72 & 80 \\
\hline Have you read any article on preventability of transfusion reaction? & 22 & 24.44 & 68 & 75.55 \\
\hline Have you ever been trained on how to report transfusion reactions? & 13 & 14.44 & 77 & 85.55 \\
\hline
\end{tabular}

\section{DISCUSSION}

Reporting of transfusion reactions is very important for the success of haemovigilance programme. Various factors have been found to be responsible for underreporting of adverse drug reactions (ADRs) by doctors. These factors are mainly related with the knowledge and attitude of doctors. ${ }^{15-18}$ This study has found not only poor practice but also inadequate knowledge regarding transfusion reaction reporting. Only $35(38.88 \%)$ of the participants were aware of the transfusion reaction reporting system in India. 27 (30\%) of the participants knew about the regional transfusion reaction reporting centre. This indicates that since haemovigilance programme has just been launched a lot of doctors are not aware of it. Therefore, increasing awareness about haemovigilance program and transfusion reaction monitoring centre (TMC) through personal communication and CME appears necessary to enhance reporting.

In this study $58(64.44 \%)$ of the doctors were of opinion that serious reactions should be reported. In order to share information and compare data, internationally accepted definitions for adverse reactions in recipients have been developed There are many different types of transfusion reactions, which can be subdivided in several ways according to their occurrence, pathogenesis and/or symptomatology. A common subdivision according to the occurrence is between acute ( $<24$ hours after) and delayed (>24 hours after transfusion) reactions. According to their pathogenesis, adverse reactions can be divided in infectious and non-infectious adverse reactions. Noninfectious acute reactions include acute haemolytic transfusion reactions (AHTR), febrile non-haemolytic transfusion reactions (FNHTR), allergic reactions including anaphylactic reactions; transfusion associated acute lung injury (TRALI), transfusion-associated circulatory overload (TACO), hypotensive reactions and hyperkalaemia. Non-infectious delayed transfusion reactions include delayed haemolytic transfusion reactions (DHTR), delayed serological transfusion reactions (DSTR), post transfusion purpura (PTP), transfusion-associated graft versus host disease (TAGVHD) and haemosiderosis. The main acute infectious adverse reactions are due to bacterial contamination of the blood component, and delayed infectious reactions may be due to viral (e.g. hepatitis B/C, HIV) or parasitic (e.g. malaria) transmission. ${ }^{1}$

This study showed that $73(81.11 \%)$ of the doctors strongly agreed that there should be blood transfusion committee in the hospital.

Hospital transfusion committee play a key role in dealing with haemovigilance and risk management, providing leadership and advocacy for transfusion practice and coordinating multi-disciplinary teams with quality and risk management tools. The hospital transfusion committee (HTC) will supervise for promoting the safe and appropriate transfusion of blood and its components. On a simplistic level, the HTC sets appropriate policies and procedures, reviews and revise them and monitors practice against them. ${ }^{11}$

The need of HTC was considered in 2002 when national blood policy was established. One of the main objectives of national blood policy is "to encourage appropriate clinical use of blood and blood products." It was suggested every institution having a blood transfusion department should comprise HTC and its role was detailed. Safety aspects of blood transfusion to be covered include identification of patient samples, bedside test, post transfusion follow-up and measures in case of an adverse reaction. The HTC should have authority within the hospital for determining hospital transfusion policy and resolving problems. ${ }^{11,12}$

In the present study $68(75.5 \%)$ and $54(60 \%)$ of the doctors were of the opinion that blood ordering schedule and group screen and hold respectively will help in better utilization of blood products. 
The surgical blood order schedule is a table of elective surgical procedures which lists the number of units of blood routinely cross matched for them preoperatively. The schedule is based on retrospective analysis of actual usage of blood in the hospital associated with individual surgical procedure. The aim of it is to correlate as closely as possible the amount of blood cross matched $(\mathrm{C})$ to the amount of blood transfused $(\mathrm{T})$. The $\mathrm{C}: \mathrm{T}$ ratio can be used to monitor the efficiency of the scheme.

The introduction of maximum surgical blood ordering schedule (MSBOS) would result in reduction in cross matching workload of blood transfusion laboratory and more efficient use of blood stocks and reduction in wastage due to outdating. ${ }^{13}$

According to Imam the reasons for underreporting of ADRs occur due to "seven deadly sins", which are complacency (Belief that serious ADRs are already documented), diffidence (belief that reporting should be done when there is certainty that reaction is caused by use of particular drug), legal aspects (fear of litigation), financial incentives ( rewards for reporting), indifference (belief that single report would make no difference), ignorance (that only serious ADRs are to be reported), lethargy (excuse about lack of time or disinterestedness). ${ }^{14-16}$ Some of these sins were also documented in studies done in Ahmadabad and Delhi. ${ }^{11,12}$

In this study complacency and ignorance about the reporting system were the main factors whereas the lethargy, financial and legal aspects were given less importance.

Suggestions given by the respondents to improve reporting corresponded with those observed in other studies for reporting of adverse drug reactions. However, according to most of the respondents, an educational intervention and training to doctors in transfusion reaction reporting can improve doctor's awareness of transfusion reactions and enable them to incorporate the knowledge into their daily clinical practices. Thus if the knowledge on transfusion reaction reporting is improved then the attitude also improves which should reflect on the transfusion reaction reporting in a positive manner. Apart from this, out of the major suggestions include reporting of transfusion reaction be made more easy, providing electronic option for submission, transfusion reaction monitoring can be improved. This improvement has been demonstrated in the study conducted to report ADR in Manipal as pre KAP and post KAP survey. ${ }^{17,18}$

In our study only $22.22 \%$ of respondents had ever reported any transfusion reaction, indicating that there is under reporting in the hospital. This finding was similar to the previous two previous studies for reporting adverse drug reactions (ADRs) which reported $19 \%$ and $15 \%$ practice respectively. ${ }^{19,20}$ In present study, $80 \%$ of doctors had never attended any CME on transfusion reaction reporting. Similarly, the South India study18 also cited similar findings that $96.7 \%$ of the respondents have never attended any CME. In the present study it was observed that $14.44 \%$ of the doctors received training on how to report transfusion reaction to haemovigilance centre.

Many patients do not have access to blood when they need it. Even where sufficient blood is available, many people are exposed to avoidable, life-threatening risks through the transfusion of unsafe blood. ${ }^{21}$

\section{The appropriate clinical use of blood requires}

- National policy and guidelines on blood transfusion

- Training of all staff involved in blood transfusion

- Availability of alternatives to blood transfusion

- Hospital transfusion committees

- Blood request form

- Maximum surgical blood ordering schedule system for monitoring transfusion practice.

\section{The safe administration of blood and blood products prevents avoidable transfusion reactions this requires}

- Standard operating procedures for blood transfusion

- Training in blood transfusion

- Haemovigilance system for monitoring, reporting and investigating adverse events associated with transfusion. $^{21}$

\section{CONCLUSION}

The present study showed that doctors were not aware about transfusion reporting system, which is responsible for poor practice about transfusion reaction reporting. Therefore, there is need to increase the awareness regarding haemovigilance programme of India through CMEs at regular interval and training the doctors on how to report a transfusion reaction and also include haemovigilance awareness programs for undergraduates. All these steps will enhance spontaneous reporting rate and safety of the patients at large.

\section{ACKNOWLEDGEMENT:}

Author wants to acknowledge all the doctors who responded promptly to the questionnaires.

\section{Funding: No funding sources \\ Conflict of interest: None declared}

Ethical approval: The study was approved by the Institutional Ethics Committee

\section{REFERENCES}

1. De Vries RRP, Faber JC, Strengers PFW. Haemovigilance: an effective tool for improving transfusion practice. The Int $\mathbf{J}$ of trans. Medicine. 2011:100;60-7. 
2. Public health service (PHS). Biovigilance working group. Department of health and human services Washington, DC20201. Biovigilance in the United States: Efforts to bridge a critical gap in patient safety and donor health; 2009:16.

3. Commission directive 2005/61/EC of 30 September 2005 implementing Directive 2002/98/EC of the European parliament and of the council as regards traceability requirements and notification of serious adverse reactions and events. Official Journal of the European Union; 2005.

4. Faber JC. Haemovigilance procedure in transfusion medicine. Haematol J. 2004;5:74-82.

5. Faber JC. The European blood directive: a new era of blood regulation has begun. Transfus Med. 2004;14:257-73.

6. Jain A, Kaur R. Haemovigilance and blood safety. Asian J Transfus Sci. 2012;6:137-8.

7. Bisht A. Haemovigilance programme of India. Available at http://www.ihn-org.com/wpcontent/uploads/2014. Accessed 11 February 2016.

8. Dheengra N. Haemovigilance in developing countries. Available at http// ihn.withtoast.co.uk/wpcontent/uploads/2011. Accessed 5 February 2016.

9. World health organization .Who draft guidelines for adverse event reporting and learning system. 2005;1-80.

10. Paula HB, Maggs B, Hannah C. Serious hazards of transfusion (SHOT) haemovigilance and progress is improving transfusion safety. British Journal of Haematology. 2013;163:303-14.

11. Kaur G, Kaur P, Hospital transfusion committee: role and responsibilities. Ind $\mathbf{J}$ of patho and Microbiology. 2014:57(2);352-3.
12. Haynes SL, Torella F. The role of hospital transfusion committees in blood product conservation. Transfus Med Rev. 2004:18;93-104.

13. Napier JAF, Boultan FE, Guidelines for implementation of a maximum surgical blood order schedule. Clin lab Haemat. 1990:12;321-7.

14. Imam WH, Attitudes to adverse drug reaction reporting. Br J Clin Pharmacol. 1996;41:433-5.

15. Desai CK, Iyer G. An evaluation of KAP of ADR reporting among prescribers at a tertiary care hospital. Perspect clin Res. 2011;2(4):129-36.

16. Rehan HS, Vasudev K, Tripathi CD. Adverse drug reactions monitoring: knowledge, attitude and practices of medical students and prescribers. The National Medical Journal of India. 2002;15(1):24-6.

17. Radhakrishnan R, Vidyasagar S. An educational intervention to asses' knowledge attitude practice of pharmacovigilance among healthcare professionals in an Indian tertiary care teaching hospital. International journal of pharma Tech research. 2011;3(2):678-92.

18. Thomas TM, Udaykumar $\mathrm{P}$, Scandashree K. Knowledge attitude and practice of adverse drug reaction reporting among doctors in a tertiary centre in south India. Int $\mathbf{J}$ Pharmacol and Clin Sci. 2013;2:82-8.

19. Kharkar M, Bowalekar S. Knowledge attitude and practice (KAP) of medical practitioners in India towards adverse drug reaction (ADR) reporting. Perspect Clin Res. 2012;3:90-4.

20. Mishra H, Kumar V. Pharmacovigilance: current scenario in a tertiary care teaching medical college in North India. J pharmacovigilance. 2013;1(2):2-4.

21. World health organization. Blood transfusion safety 2006 Available www.who.int/bloodsafety/en/Blood_Transfusion_Saf ety.pdf. Accessed 2 February 2016.

Cite this article as: Date AP, Date AA, Dashputra AV, Borkar AS. Knowledge attitude and practice of haemovigilance among doctors in tertiary care hospital in Nagpur, Maharashtra, India. Int J Basic Clin Pharmacol 2016;5:788-93. 